\title{
Temperature Distribution Characteristics of Asphalt Pavement Based on the Field Measured Data
}

\author{
Shenbo Zhou', a, Shengjie Liü, b \\ ${ }^{1}$ Guangxi Key Laboratory of road structure and materials, Nanning, Guangxi, 530007, China; \\ ${ }^{2}$ College of Civil and Transportation Engineering, Hohai Univ., Nanjing 210098, P.R. China. \\ azhoushengbo2005@163.com, 'lsjwork@126.com
}

\begin{abstract}
The aim of this study is to evaluate pavement temperature distribution by in-situ testing. Temperature data were collected and analyzed at daily, monthly and yearly time scales based on the Gan-Chong highway. The test results on the temperature data indicated that pavement temperature in different depth showed a similar change tendency, while in the high or low temperature season, the pavement temperature is still in the middle temperature range.
\end{abstract}

Keywords: Road engineering; Asphalt pavement; Temperature distribution; in-situ testing.

\section{Introduction}

The temperature profile within the asphalt layer of a flexible pavement plays an important role in the design of hot-mix asphalt and in the performance models of asphalt concrete materials [1], as the viscoelastic behavior of asphalt concrete can significantly vary by temperature variation $[2,3]$. Due to the viscoelastic plastic materials of asphalt mixture, the strength and modulus are different under the various temperatures [4]. As results of that, a different types of flexible pavement damage will appear. For example, the pavement will be cracking at low temperatures, and be rutting in high temperatures [5]. So the pavement temperature influence on bearing capability and performance of asphalt pavement cannot be ignored. In order to determine in-situ strength characteristics of flexible pavement, it is necessary to know the temperature distribution within the HMA layers.

The research on pavement temperature have already begun in very early, while many temperature models have been developed to predict the pavement temperature distribution[6-8]. However there are many defects in these prediction models to make it difficult to predict accurate the actual temperature for a specific pavement[9], because the models can not reflect all the factors effect the temperature distribution of flexible pavement by environmental conditions[10]. So in order to obtain true pavement temperatures, the temperature sensors distributed sensing technique is used to make practically continuous measurement.

The current study aims at investigating the real temperature distribution under the different environmental conditions. Testing was conducted in an effort to get the temperature data within the HMA layers of various pavement cross-sections. This paper presents the temperature distribution characteristic at daily, monthly and yearly time scales based on the measured data.

\section{Research methodology}

Gan-Chong highway, in Ganzhou, Jiangxi Province, was used for the testing of pavement temperatures. The pavement structure and the sensors position are shown in Figure 1. The parameters of the NTC (Negative Temperature Coefficient) sensor used in this study as follows: measuring range $-40 \sim 100^{\circ} \mathrm{C}$, measurement accuracy $\pm 0.2^{\circ} \mathrm{C}$, storage capacity 33000 group, measurement resolution $0.1^{\circ} \mathrm{C}$. For the continuous measurement will produce large amount of data, $30 \mathrm{~min}$ was set as the time sample interval. 


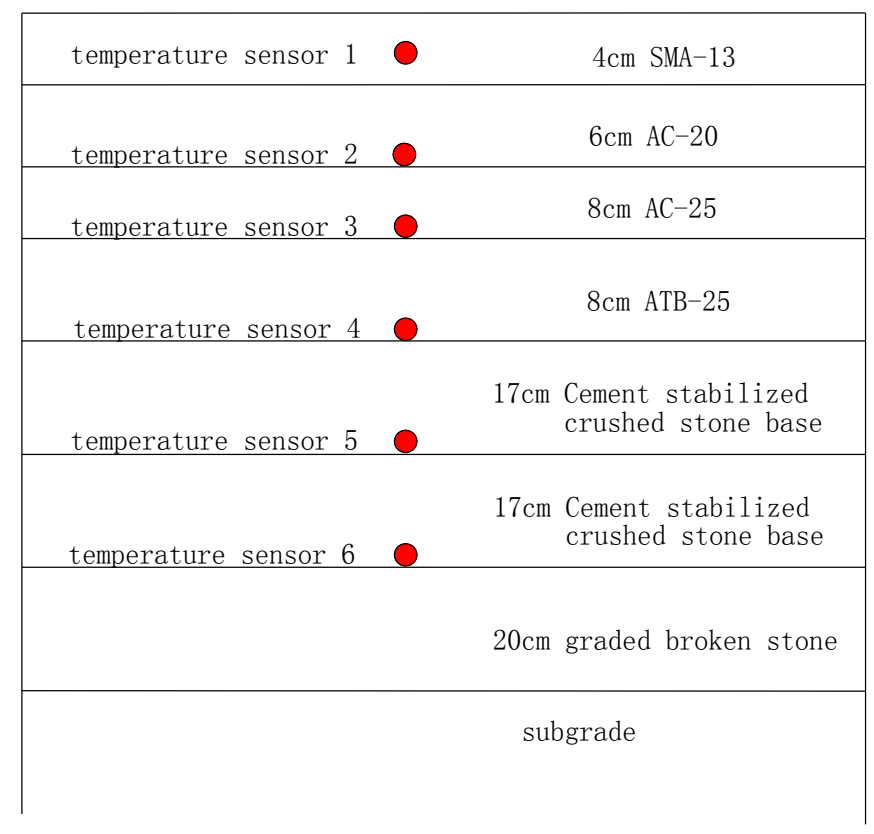

Fig. 1 Asphalt pavement structure and temperature sensor position

\section{Daily Pavement Temperature Distribution Characteristic}

The diurnal variation of external temperature is influenced by many factors especially the weather factor, so most of the previous studies aimed at sunny days to avoid the weather affected [11]. In this research, the daily pavement temperature characteristic was analyzed for the June 11, 2014 (sunny).To give a statistical characterization of the temperature parameters, line chart were created based on temperature data from 0:00 to 24:00. Figure 2 gives the distribution of the diurnal pavement temperature change at different depths of Gan-Chong highway. It can been seen that pavement temperature show an evident difference at different times, the maximum daily surface pavement temperature $(2 \mathrm{~cm})$ exceeds $40{ }^{\circ} \mathrm{C}$, while $15{ }^{\circ} \mathrm{C}$ higher than minimum daily surface pavement temperature, temperature of other pavement depths reflect the similarly law only the amplitude of variation is different.

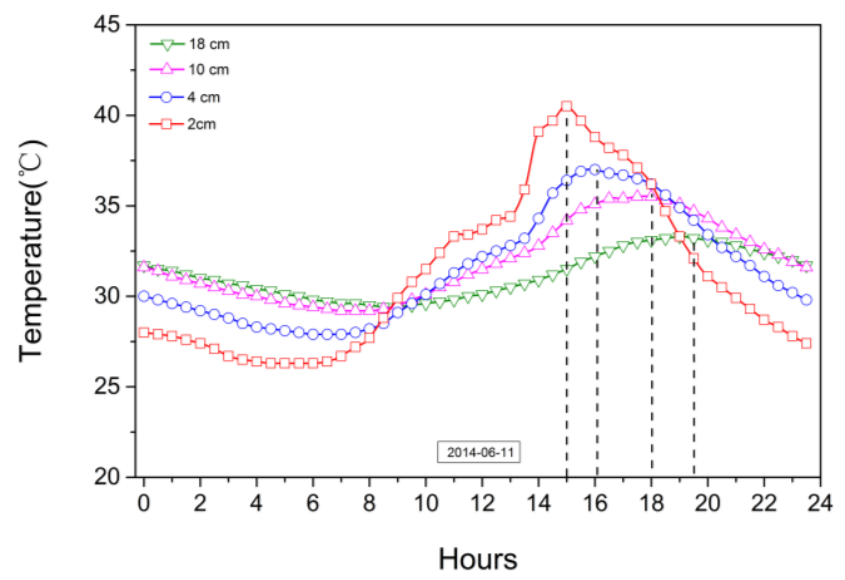

Fig. 2 Distribution of daily pavement temperature

In general, it is found that before 6:00, the temperature of pavement structure has been decreasing with time. After 8:00, the pavement structure temperature begin to rise, while the highest pavement temperature appeared at 15:00 to 18:00. It is found that the temperature change of the pavement surface or the upper pavement layer is more severe, and the middle surface layer or the lower layer is relatively stable. The large pavement differences following times are attributed to heating by solar radiation, while the pavement temperature distinctions at various depths are attributed to thermal conductivity difference. 


\section{Monthly Pavement Temperature Distribution Characteristic}

Temperature effect on asphalt pavement is not only caused by the representative temperature (maximum and minimum temperature), but also by the temperature frequency distribution characteristics. For the same asphalt pavement, even if the highest and lowest temperature are similarly, different temperature frequency distribution will also lead to significantly differences on the pavement distress degree. Therefore, in order to better predict the asphalt pavement disease, it is necessary to research the temperature distribution characteristics considering temperatures distribution.

Monthly temperature data of the upper layer $(2 \mathrm{~cm})$ were collected from January 2013 to December 2013. Through analyses and study, it is found that the maximum temperature is $39.6^{\circ} \mathrm{C}(2013.8 .10)$, comparing that the minimum temperature is $-1.5^{\circ} \mathrm{C}(2013.12 .28)$, and the yearly average temperature is $21.2^{\circ} \mathrm{C}$. In order to have a better understand of the pavement temperature distribution in different month, the probability density distribution of pavement temperature is statistically as shown in Figure 3.

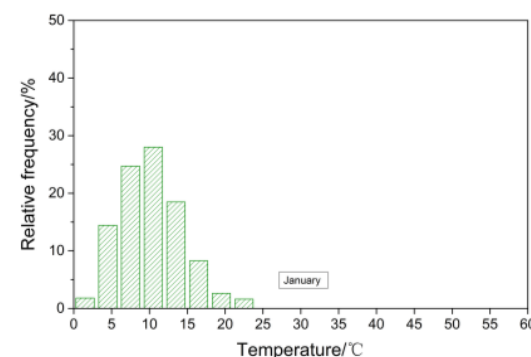

(a)January

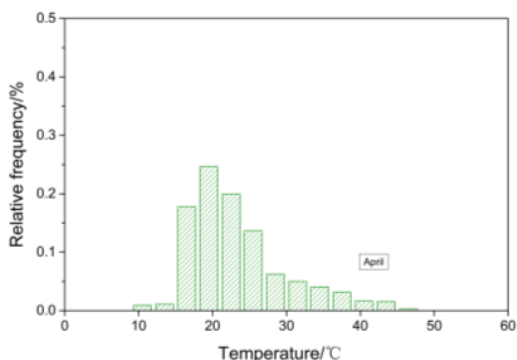

(d)April

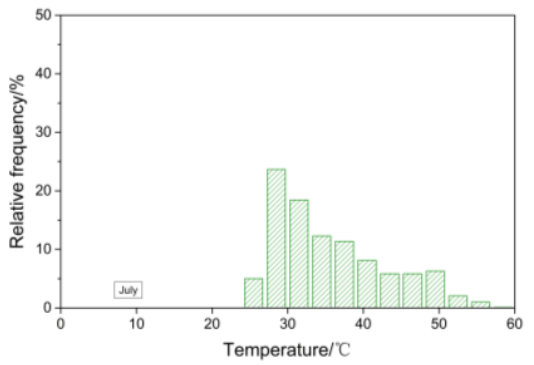

(g)July

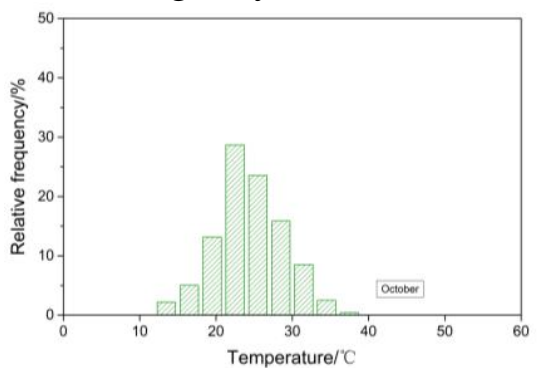

(j)October

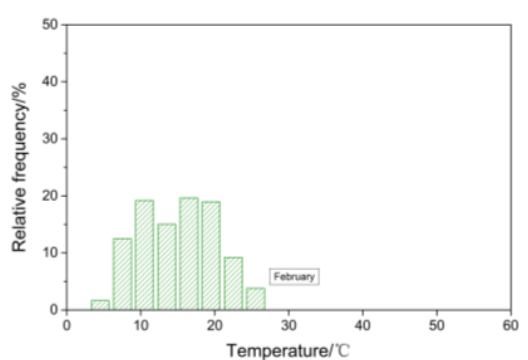

(b) February

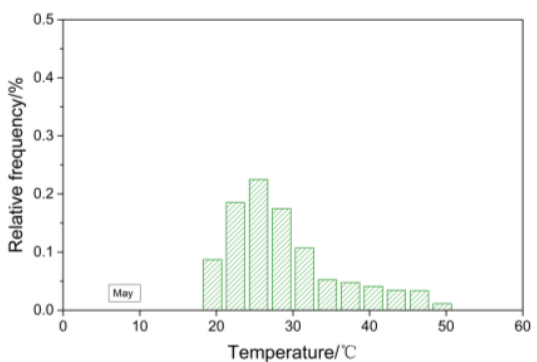

(e) May

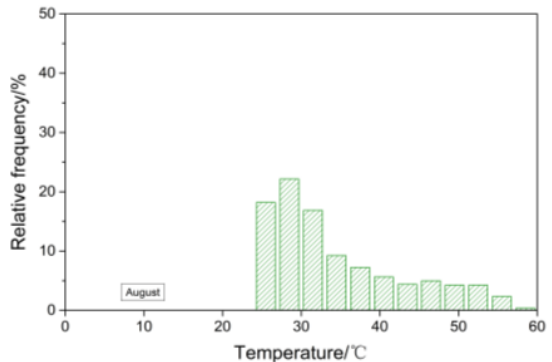

(h) August

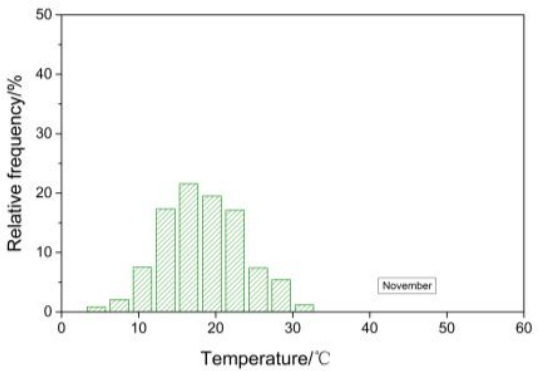

(k) November

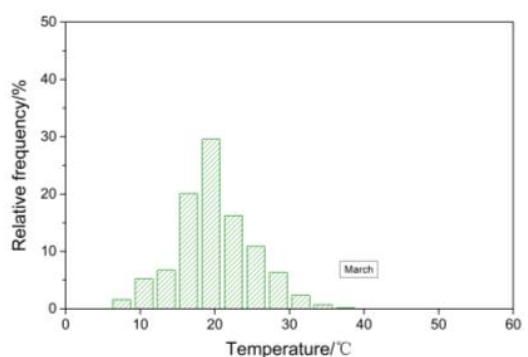

(c) March

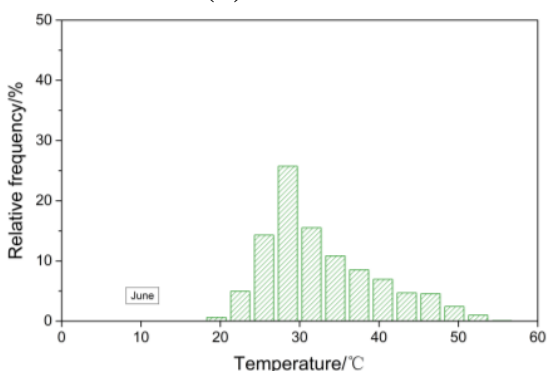

(f) June

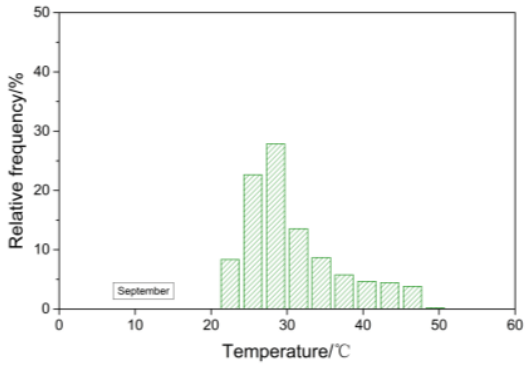

(i) September

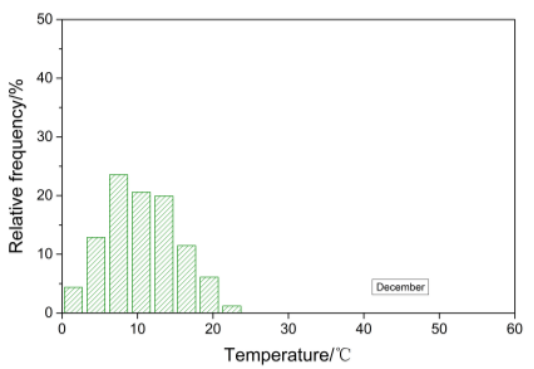

(l) December

Fig. 3 Monthly temperature distribution characteristics 
From Fig. 3, it can be seen that the change law of pavement temperature at different months. The distribution of pavement temperature is mainly from the middle and low temperature $\left(0-25^{\circ} \mathrm{C}\right)$ to the high temperature shift from January to August, then the temperature gradually moved toward the low temperature after September. The pavement temperature range of the whole year is between $0-60^{\circ} \mathrm{C}$, it can be known that the pavement suffer complex temperature changes in one year.

\section{Conclusion}

Pavement temperature distribution characteristics were evaluated and compared in this paper. Based on these test results, some conclusions and recommendations can be drawn.

(1) Pavement temperature in different depths showed the similar change tendency, while due to the differences of heat conductivity, there is a phase between the temperature change curves in different depths.

(2) In the whole year, the maximum highest temperature value of the asphalt pavement appeared in August and the lowest value appeared in December.

(3) From the daily maximum temperature distribution frequency, it can be known that in the high or low temperature season, the pavement temperature is still in the middle temperature ranges, while the weather patterns have a direct influence over temperature distribution.

\section{Acknowledgements}

The research presented herein was sponsored by the Fundamental Research Funds for the Central Universities (2015B11614) and by the Foundation of Guangxi Key Laboratory of road structure and materials (2015gxjgclkf-005).

\section{References}

[1]. Mammeri, A., Ulmet, L., Petit, C., etc. Temperature modelling in pavements: the effect of long-and short-wave radiation. International Journal of Pavement Engineering, Vol. 16 (2015) No. 3, p. 198-213.

[2]. Tchemou, G., Seba, L., Iabse, M., etc. Prediction of Flexible Pavement Degradation: Application to Rutting in Cameroonian Highways. Electronic Journal of Geotechnical Engineering. Vol. 16 (2011) p. 1301-1319.

[3]. Nguyen, Q. T., Di Benedetto, H., Sauzéat, C. Linear and nonlinear viscoelastic behaviour of bituminous mixtures. Materials and Structures. Vol. 48 (2015) No.7, p. 2339-2351.

[4]. Gupta, A., Kumar, P., Rastogi, R. Critical review of flexible pavement performance models. Ksce Journal of Civil Engineering.Vol. 18 (2014) No.1, p. 142-148.

[5]. Hou, H., Wang, T., Wu, S., etc. Investigation on the pavement performance of asphalt mixture based on predicted dynamic modulus. Construction and Building Materials.Vol. 106 (2016) No.1, p. 11-17.

[6]. Abo-Hashema, M. A. Modeling Pavement Temperature Prediction using Artificial Neural Networks. American Society of Civil Engineers. (2014), p. 490-505.

[7]. Cao, L., Dong, Z., Sun, L. Permanent Deformation Characteristic of Asphalt Mixture Considering Pavement Temperature Distribution. In Ninth International Conference of Chinese Transportation Professionals (ICCTP) [C], Harbin, China, 2009, p. 1-8.

[8]. Cheng, J., Qian, X. Temperature-dependent viscoelastic model for asphalt concrete using discrete rheological representation. Construction and Building Materials.Vol. 93 (2015), p. 157-165. 
[9]. Wang, D. Simplified Analytical Approach to Predicting Asphalt Pavement Temperature. Journal of Materials in Civil Engineering.Vol. 27 (2015) No.12, p.04015043.

[10]. Toraldo, E., Mariani, E., Alberti, S., etc. Experimental investigation into the thermal behavior of wearing courses for road pavements due to environmental conditions. Construction \& Building Materials.Vol. 98 (2015), p.846-852.

[11].Hsu, C.-Y., Chen, S.-H., Lin, J.-D., etc. The In-Situ Temperature Evaluations of Permeable Pavements in summer. Journal of marine science and technology-taiwan.Vol. 25 (2015) No.3, p.288-292. 